\title{
A NOTE ON METHODS FOR THE CHEMICAL PURIFICATION OF DRINKING WATER.*
}

\author{
Bx A. WARNER, M.D., M.R.C.S.
}

THe prevalence of typhoid fever amongst our troops during the present campaign in South Africa has directed special attention to the methods available, under the conditions of active service in the field, for checking the spread of the disease so far as the purification of drinking water is concerned.

These methods include heat-sterilization by portable apparatus of the Vaillard-Desmaroux type, by means of which a supply of sterilized water may be obtained at the rate of something like 1,000 litres per hour; sterilization by filtration through Berkefeld or Pasteur-Chamberland bougies, used either by individuals as pocket-filters or in batteries for the filtration of large quantities; and, finally, purification by the addition of chemical reagents.

The general practicability of these methods under the given conditions has been fully dealt with in a recent paper by Major Macpherson, M.B., ${ }^{1}$ and the various difficulties attending on the use of all three methods pointed out.

The following experiments, which it is hoped will be of some interest to readers of Public Heatri, were carried out in order to test the efficiency of two methods of chemical purification which have been recently suggested.

Purification by the Use of Actd Sulphate of Soda.

In a paper read before the Epidemiological Society, ${ }^{2}$ Louis Parkes, M.D., and S. Rideal, D.Sc., recommend the use of tabloids of bisulphate of soda, three tabloids being used to each pint of water, and fifteen minutes' contact being allowed before drinking. It is suggested that "the tabloids should be put up in well-made, light metallic boxes to hold about a quarter of a pound weight, equivalent to 350 tabloids-enough to sterilize over 100 pints of water at the rate of three per pint."

The writers further state that " the Bacillus typhosus is killed by only five minutes' contact with sodium bisulphate in the proportion

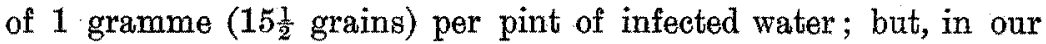
opinion, it is better that contact should be made for fifteen minutes in order that sterility may be insured."

The action of the bisulphate when used in this manner has been

* From the Bacteriological Laboratory of the Middlesex Hospital. 
tested on the four following organisms: Bacillus typhosus, B. enteritidis (Gärtner), B. coll communis, and B. cholere.

The experiments were carried out in the following manner :

1. Two flasks, A and B, each containing 568 e.c. of tap-water, were sterilized.

2. To flask $A$ was then added 1 gramme of sodium bisulphate, which was allowed to dissolve.

3. Flask A was then inoculated with $0 \cdot 1$ c.c. of a broth culture of the organism to be tested. Flask $B$ was inoculated with the same quantity at the same time, and used as a control. The broth cultures were in every case used after twenty-four hours' incubation at $37^{\circ} \mathrm{C}$.

4. At intervals of five, ten, fifteen, etc., minutes, $0: 1$ c.c. of the infected water was withdrawn from each flask, added to a tube of melted gelatin, and poured out in a Petri dish.

5. These plate cultures were then incubated for ninety-six hours at a temperature of $22^{\circ} \mathrm{C}$, at the end of which time the number of colonies from the respective samples taken from the two flasks was counted.

The following table gives examples of the results obtained: Four of the experiments in which $B$. typhosus was used are recorded, the figure of the third experiment giving the average of the count of two plates for each period of exposure, and that of the fourth giving the average of three plates.

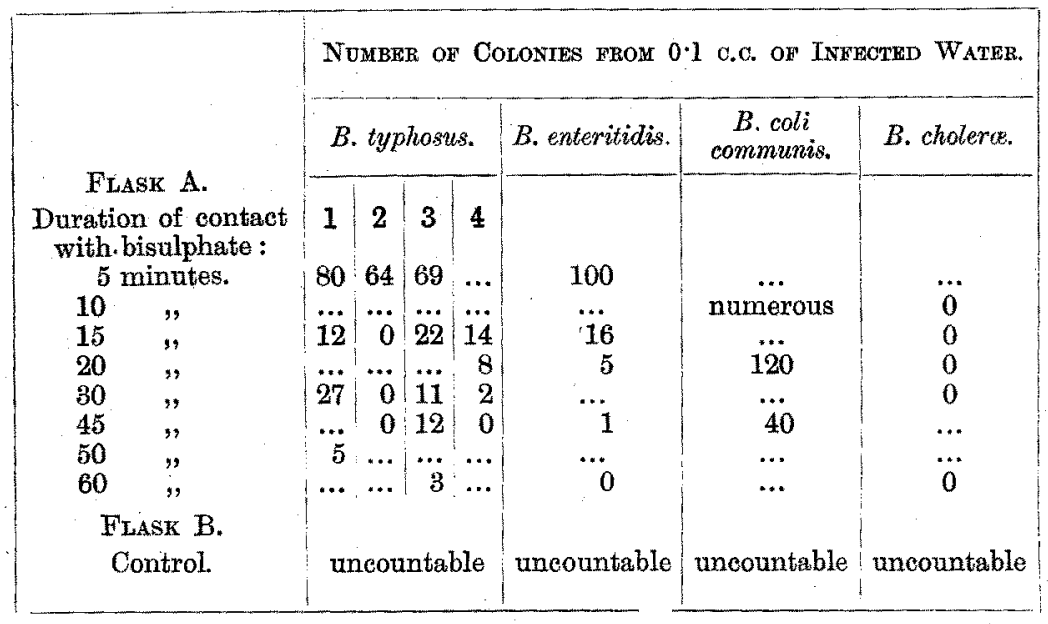

In a number of other experiments carried out with B. typhosus, the quantities and the times of exposure, etc., being the same as in those previously quoted, it was found that contact with the bisulphate 
of soda for thirty minutes was followed by complete sterilization of the water in the majority of the tests.

All the experiments were carried out with good tap-water containing the additional organic matter represented by $0 \cdot 1$ c.e. of the broth culture, and it is a question whether the presence of large quantities of organic matter, as would frequently occur under the conditions in which the use of the method is suggested, would not impair to a certain extent its efficiency.

The experiments show that a contact of fifteen minutes with the bisulphate causes a striking reduction in the number of baeilli present, but certainly does not "sterilize" water containing $B$. typhosus; but a contact of thirty minutes does undoubtedly, in the majority of instances, destroy $B$. typhosus in a tap-water under the conditions of the experiment. A contact of ten minutes is sufficient to destroy $B$. cholere, whilst $B$. enteritidis exhibits a resistance very much of the same degree as $B$. typhosus. B. coli communis is, as might be expected, rather more resistant than the other bacteria used.

The method suggested by Drs. Parkes and Rideal will, then, very materially reduce the risk of infection by $B$. typhosus in drinkingwater, but a minimum exposure to the bisulphate of thirty, not fifteen, minutes is necessary.

The applicability of the method to the needs of actual service in the field can only be judged by medical officers familiar with those needs, but the following objections to its use may be pointed out:

1. Any method which rests on the initiative of the individual soldier is likely to prove futile. Thus, in emphasizing the objections against the use of filters, the writers quoted say "it is very doubtful if men, parched by long marches performed under a fiery sun and in clouds of dust, can be restrained from slaking their thirst as soon as they arrive at water ... The agonies of thirst are intense, and at the time far outweigh any such considerations as those of prospective illness from the consumption of a germtainted water," and it is doubtful whether the men would restrain themselves for the thirty minutes necessary for the action of the bisulphate.

2. Assuming that the necessary thirty minutes' contact will be given, it is still doubtful whether, for other reasons, the use of the tabloids would be favourably looked upon. The writers describe the tabloids as "imparting a subacid flavouring, which is agreeable to the taste, and would materially aid in quenching thirst." To some people, however, the taste imparted to the water by the bisulphate is unpleasant, and would probably become irksome after 
the twenty days' continuous use suggested in the paper referred to. The writers suggest that a soldier would drink about 5 pints of the water a day, and it is quite possible that the addition to the drink of 75 grains per diem of such a salt as sodium bisulphate would have the effect of increasing the sense of thirst rather than of quenching it, especially if its administration was continued for twenty days.

Beyond all this lies the question as to the extent to which enteric fever in the South African campaign has been a water-carried disease. Until this question is settled, if it ever be, it would be unwise to adopt, possibly to the exclusion of other methods, a means of prevention which would probably not be effectually carried out, and is directed against one source of infection only. There is reason to hope that, in the next campaign in a similar climate in which our troops are engaged, a more efficient protection against typhoid infection from every source will be afforded by preventive inoculation.

Whilst, therefore, the use of the method for the particular purpose suggested by Drs. Parkes and Rideal is open to objection, the experiments carried out have suggested that it may have a future before it for another purpose. The disinfection of contaminated water-supplies, and notably of cholera-contaminated wells, presents a problem of some difficulty, which has not been solved to complete satisfaction by the use of permanganate of potash. The destructive action of the bisulphate on $B$. cholere was very marked, and if it can be shown that this action is not materially affected by the presence of a moderate amount of organic matter in the water, and if the expense of using it is not prohibitive, it is not unlikely that the salt would effect disinfection of contaminated wells more thoroughly than the permanganate at present in common use in India for the purpose.

\section{Emergency Purification of Water by the Method of LAPEYRÈRE.}

In a paper read in the subsection for Military Hygiene of the Congress of Medicine, held in Paris last year, Lapeyrère suggested a new method for the purification of water for the use of troops on active service. ${ }^{3}$

A powder consisting of permanganate of potash 3 grammes, aluminate of soda 10 grammes, carbonate of soda 9 grammes, carbonate of lime 3 grammes, is added to 100 litres of water. After standing for a few minutes the water is passed through a filter constructed of a drum of unoxidizable metal, packed with 
purified peat fibre mixed with black oxide of manganese. This process is said to combine sterilization of the water with precipitation and clarification. Only the first of these was tested.

Experiment 1.-Two wash-bottles were taken and connected by tubing in the length, of which 6 inches of $\frac{3}{4}$-inch glass tubing, elosely packed with peat fibre and manganese dioxide, was interposed. The whole apparatus was then sterilized. 568 c.c. of tapwater were then added to one of the bottles, then 0.1 c.c. of a twenty-four-hour old culture of B. typhosus, and then Lapeyrère's powder in the proportion advised. After standing for fifteen minutes the mixture was driven slowly through the filter from one flask into. the other. Gelatin plates were prepared, each from 01 c.e. of the filtered water. These were incubated for seventy-two hours at $22^{\circ} \mathrm{C}$, and at the end of that time showed the growth of numerous. colonies of bacteria, including several identified as B. typhosus

Experiment 2.-The experiment was then repeated in a similar way, except that the tap-water was sterilized before the eulture of $B$. typhosus was added to it, and that the water was drawn very slowly through the closely-packed filter at the rate of 200 c.e. per hour. Gelatin plates were made as before, and on counting them, after seventy-two hours' incubation, twenty-three colonies of $B$. typhosus were found on one plate and eleven on another. In view of these results, it was not thought worth while to carry the experiments any further, as it was obvious that, under the very favourable conditions of the slow filtration, the process did not get, rid of all the pathogenic bacteria present.

1 Publto Health, 1901, vol. xiii., p. 618.

2 Trans, Epidem. Soc. Lond., N.S., vol. xx., 1900-1901.

3 Ptiple Heater. 1901, vol. xiii., p. 296.

Bacterionogy of Rhedmatrsir.-F. Meyer (Deutsche Med. Wochenschrift, February 7th, 1901) states that in investigating cases of acute. articular rheumatism bacteriologically, after unsatisfactory results from the direct examination of the joint exudate, he made cultures from the tonsils, and discovered practically regularly the presence of a diplo-. coceus which grew in chains, and which in its bacteriological characteristies had a close resemblance to the organism previously described by Wassermann, but was not identical with it. This organism. was not found on the tonsils of persons who had not acute rheumatism. When injected into animals it produced a seropurulent exudation in the joints, which was usually sterile. In about one-fifth of the animals so: injected there was a verrucose or ulcerative endocarditis. He does not think that one can yet state positively whether the streptococcus is actually the cause of rheumatism, or, if it is the cause of rheumatism, whether it is the only cause. The number of cases as yet investigated. is too small.-Amer. Jour. Med. Sc. 